\title{
How is Greece conforming to Alma-Ata's principles in the middle of its biggest financial crisis?
}

The international Alma-Ata conference held on September 1978 by the World Health Organisation (WHO) set equity, comprehensiveness, continuity of care, and patient centeredness, as targets for all health systems in the world. ${ }^{1}$ In order to achieve these targets, it mobilised a 'primary healthcare movement' that shifted global thinking about health from specialist, tertiary care towards ambulatory care. ${ }^{2}$ WHO's report of 2008, Primary Health Care: Now More Than Ever, ${ }^{3}$ reconfirmed WHO's adherence to primary health care as the only way for health systems to respond to the challenges of a changing world. How has Greece dealt with Alma-Ata's principals for the last 30 years? And how relevant are these principles today, in the middle of the country's biggest financial crisis?

\section{THE GREEK PRIMARY HEALTH CARE}

Inspired by Alma-Ata's ideals, Greece instituted a national health system in 1983, so that it could 'guarantee that all citizens enjoy the benefits of a complete range of services of high quality, free at the point of service'. ${ }^{4}$ Since then, the Greek NHS has been providing free access and full coverage to the entire population, including immigrants. Within NHS or social insurance context, primary healthcare services are delivered through health centres and provincial surgeries in rural areas and through outpatient departments of regional and district hospitals, polyclinics of the social insurance institutions and contracted physicians and diagnostic centres in urban areas. There are also many private physicians and diagnostic centres that provide services directly to the population.

A major shortcoming of the Greek healthcare system is that most public and private primary care services are staffed almost exclusively with specialists, who are therefore the first point of contact. Greece has the largest number of specialists per population among all OECD (Organisation for Economic Cooperation and Development) countries (3.3 per 1.000 population according to 2005 data). ${ }^{5}$ Greek citizens are unfamiliar with GPs. It is notable that less than $3 \%$ of the doctors in Greece are GPs, a specialty that is not highly esteemed among the health professionals. Patients have direct access to secondary care as there is no gatekeeping system.

One of the main characteristics of the Greek healthcare system is its hospitalcentred $^{6}$ orientation, and its substantial underfunding of public primary care services. ${ }^{7}$ Rural health centres operate without adequate staffing and diagnostic equipment, whereas provincial surgeries are staffed with medical graduates characterised by lack of clinical experience. In urban areas, hospital outpatient clinics and social fund polyclinics are incapable of satisfying the demand for public primary healthcare services, resulting in long waiting lists and causing discomfort to citizens.

However, the most important obstacle in producing scientific sound, public primary healthcare services of high quality is probably related to their inadequate organisation frameworks. Management strategies are obsolete, educational and training programmes are partial and incomplete, and mechanisms for supervising and evaluating medical practices are completely absent. There are no effective systems of keeping, organising, and coordinating medical records, measuring how health resources are used, and assessing and monitoring the outcome of care. ${ }^{8}$ Practice guidelines, and diagnostic and therapeutic protocols have rarely been used, ${ }^{9}$ whereas prescribing patterns are rather idiosyncratic. Additionally, primary healthcare services do not provide any positive incentives for care providers to improve their services.

\section{ADAPTATION TO ALMA-ATA'S PRINCIPLES}

Free provision of public primary healthcare services is hindered, by significant, informal, out-of pocket payments, ${ }^{10}$ raising serious issues of equity. Patients are often asked or feel obliged to pay directly additional fees, as gifts, to physicians, to get access to public healthcare services that are theoretically free of charge, despite the fact that the NHS personnel is supposed to be paid exclusively by state salaries. Illegal payments are estimated by family income surveys to be more than $20 \%$ of the total private expenditure. ${ }^{11}$ Although there is limited evidence on how informal payments affect access and utilisation of health services, it is clear that patients who cannot afford to pay cannot access the same level of services or have to wait longer for care. ${ }^{12}$ The increasing use of private health services within the Greek health system is considered another major cause of pro-rich inequality. ${ }^{13}$ Private offices visits are estimated to 25-27 million per year, a number that corresponds to $30 \%$ of total health visits.

Another serious drawback in the quality of primary healthcare services offered to the Greek population is the lack of comprehensiveness. Primary healthcare services usually provide fragmented, impersonal care and do not bear responsibility for the patient as a whole. ${ }^{14}$ They are mainly staffed with specialists, trained at various hospital settings, totally different to a primary healthcare environment, and cannot therefore provide holistic care and cover for the whole range of health needs. This fact, together with the absence of a healthcare team comprising of physicians, community nurses, health visitors, social workers, 
psychologists and other health professionals explains why Greek primary healthcare services rarely engage in any promotive, preventive, palliative or rehabilitative activities.

The Alma-Ata's targets of patientcenteredness and continuity of care have also failed to be met. The lack of some kind of personal or family doctor hinders the development of a stable, humane, long-term patient-provider relationship. The Greek population are not registered with a single-provider, and they are selfreferred to different specialists and services, according to perceived need. This often results in inconsistent management of the same episode of care and poor coordination of different episodes of care. The problem is exacerbated by poor information transfer systems both between primary care providers and between primary and secondary care, leading to possible medical errors, delays in diagnoses and unnecessary duplication of acts, examinations and prescriptions. ${ }^{15}$

\section{ECONOMIC CRISIS AND ALMA-ATA}

Greece is undoubtedly confronted by its biggest economic crisis in modern history. According to many politicians, journalists and political and economical analysts, one of the basic causes of the country's vast public debt and deficits is the notably ineffective and unproductive public administration. The structure and organisation of most Greek public institutions is considered immensely bureaucratic and corrupted, marked by a lack of adequate systems of documentation, assessment, control, and regulation. Policies are shaped more by leaders own perceptions, public opinion pressure and professional and financial interests and less by a rational system of priority setting and strategic decision making.

The Greek health sector is no exception. The satisfactory health indicators are mostly attributed to the good climate, the relatively high quality of life and the rather healthy nutrition. ${ }^{16}$ Despite the fact that the total health spending accounted for $10 \%$ of GDP in Greece in 2004, one percentage point higher than the average of $8.9 \%$ in
OECD countries, the quality of care is considered inadequate. The largest insufficiencies in the public sector are located in primary health care; ${ }^{17}$ Greece has not yet fully established an integrated, consistent, equitable, comprehensive, and patient-centred primary health care, free at the point of use.

There are fears that the fiscal crisis will lead to a cost containment policy that will further deteriorate the quality of health services and put social justice at stake. However, there is another solution: as a growing body of empirical work suggests, health systems that embrace the values of Alma-Ata Declaration regarding primary care are generally associated with better health indicators and lower costs for all medical services. ${ }^{18}$ So, the only way to provide an effective and efficient health system closer to meeting people's needs and expectations is by relocating its entry point from hospitals and specialists to close-to-client generalist primary care units, with the personal physician having a central role. The development of new managerial practices and the rapid modification of organisational policies, work procedures and hierarchical structures is urgently needed.

\section{Nikolaos Oikonomou and Anargiros Mariolis}

\section{REFERENCES}

1. Primary health care: report of the International Conference on Primary Health Care, Alma-Ata, USSR, 6-12 September, 1978, jointly sponsored by the World Health Organization and the United Nations Children's Fund. Geneva, World Health Organization, 1978 (Health for All Series No. 1).

2. Lawn JE, Rohde J, Rifkin S, et al. Alma-Ata 30 years on: revolutionary, relevant, and time to revitalise. Lancet 2008; 372(9642): 917-927.

3. The World Health Report 2008. Primary health care, now more than ever. Geneva: WHO, 2008. http://www.who.int/whr/2008/en/index.html (accessed 12 May 2010).

4. Ministy of Health and Welfare. Bill for act of Greek Parliament number 1397/83, National Health System. Athens: Registry of Greek House of Parliament, 1983.

5. OECD. OECD Health Data 2009: Statistics and Indicators for 30 Countries.

http://www.oecd.org/document/30/0,3343,en_2649_3 4631_12968734_1_1_1_37407,00.html (accessed 12 May 2010).

6. Adamakidou T, Kalokerinou A. New health policies on primary health care in Greece. Health Science Journal 2010; 4(1): 15-23.

7. Souliotis K, Lionis C. Creating an integrated health care system in Greece: a primary care perspective. J Med Syst 2005; 29: 187-196.

8. Mossialos E, Allin S, Davaki K. Analysing the Greek health system: a tale of fragmentation and inertia.
Health Econ 2005; 14(Suppl 1): S151-S168.

9. Lionis C, Symvoulakis EK, Markaki A, et al. Integrated primary health care in Greece, a missing issue in the current health policy agenda: a systematic review. Int J Integr Care 2009; 9: e88.

10. Siskou O, Kaitelidou D, Papakonstantinou V, Liaropoulos L. Private health expenditure in the Greek health care system: where truth ends and the myth begins. Health Policy 2008; 88(2-3): 282-293.

11. Liaropoulos L, Siskou O, Kaitelidou D, et al. Informal payments in public hospitals in Greece. Health Policy 2008; 87(1): 72-81.

12. Murthy A, Mossialos E. Informal payments in EU Accession Countries. Euro Observer 2003; 5(2): 1-3.

13. Tountas Y, Dimitraki C, Oikonomou N, et al. Health services in Greece 1996-2006. Athens: Centre for Health Services Research, 2008.

14. Oikonomou N, Mariolis A. Three trends that undermine the Greek health system: is there a way out? Eur J Gen Pract 2009; 15(2): 67-68.

15. Economou C, Giorno C. Improving the performance of the public health care system In Greece. Organisation for Economic Co-operation and Development, Economics Department, Working Paper No. 722, 21-Sep-2009.

16. Tountas Y, Karnaki P, Pavi E. Reforming the reform: the Greek national health system in transition. Health Policy 2002; 62: 15-29.

17. Kyriopoulos JE, Tsalikis G. Public and private imperatives of Greek health policies. Health Policy 1993; 26(2): 105-117.

18. Starfield B, Shi L. Policy-relevant determinants of health: an international perspective. Health Policy 2002; 60(3): 201-218.

DOI: 10.3399/bjgp10X509711 